\title{
Impact of Culture on Organizational Development: Case Study Kosovo
}

\author{
Veton Jahmurataj \\ Universiteti "HaxhiZeka"-Pejë, Kosovo \\ veton.jahmurataj@gmail.com
}

\section{Doi:10.5901/ajis.2015.v4n2s1p206}

\begin{abstract}
In today's environment of competitive business, the level of satisfaction of the requirements of the market is an increasingly more important element for organization to be effective. For this reason, each enterprise has its culture which provides the basis for the recognition of behavior in it and one of the key factors for its success. In the literature we often encounter the culture in terms of environment in which enterprises operate, but often the object of our study was the culture in the society. However, the culture can be discussed in the context of its impact on an enterprise, and that in essence it does not differ from the discussion of culture in the society. Also the in an enterprise is based on certain values and norms. Since studies have shown that companies that have been successful in the market for a long time have had a strong organizational culture but also adaptable, we will try that through this paper to analyze how culture affects on an enterprise, giving the fact that culture has a significant impact, both on the organizational effectiveness of competitive advantage or as a controlling and integrated mchanism in a business organization. We Will also understand how organizational culture can facilitate but also prevent changes in organizations with an enterprise culture, and those organizations with a rigid culture such as bureaucratic organizations. Through this work we aim to answer several research questions related to organizational culture in an enterprise, with a special emphasis in Kosovo. This project shows which factors affect organizational culture, as we view the organizational culture, as a whole of values, traditions, norms, standards of conduct, and common expectations within an enterprise. To achieve this goal we stop pause to review the factors that influence organizational culture in an enterprise, and finally to identify the impact of dimensions of organizational culure on the organizational effectiveness in enterprisess in Kosovo.
\end{abstract}

Keywords: organizational culture, enterprise, bureaucratic organizations, venture.

\section{Introduction}

Organizational culture is important resource of the control when exists at workers a cohesive force and all are focused at what's the best for the enterprise. Managers at the enterprise through values and norms control the results. Values are believes and ideas for the type of goals that members of one society should follow as well as for the type of behavior that people should apply to fulfill their intentions. While norms are written rules or instructions to fulfill intentions within the enterprise.

Except the values and norms it is necessary also the socializing within the enterprise which presents a process through which the new employees learn values and norms of the enterprise and gain knowledge for needed organizational behavior for effective realization in the enterprise.

Therefore in reality we notice that organizational structure influences in productivity and performance of the enterprise and gives instructions for client care and service, quality of product and security, frequenting and punctuality as well as concern for environment. She also lies in producing methods, marketing and commercials practices and also in creating of new product.

So the main goal of our study is studying of organizational culture in enterprise having traversed organizational culture and its dimensions as sustainability, compatibility, mission and involvement which are unique for every enterprise and organizational effectively in enterprises in Kosova.

\section{Meaning and Importance of Organizational Culture}

Organizational culture present altogether of values, norms, behavior standards and common expectations which control manner how individuals or groups in one enterprise communicate between each other and work for realizing of goals of organization (Rejnald. M \&Gerdi. L, 2011). Therefore the organizational culture within the enterprise is perception of 
employees and the manner how this perception creates models of trust, values and expectations. This type of control is not external as direct supervision or procedures and rules but despite the workers in internal manner in the enterprise built organizational values and norms which they trust and with them they lead actions and decisions. As it people behave in society with harmony with norms of social behavior for ex. Norms that people pay at the supermarket they should stay on the line so also the workers in one enterprise know the importance and the power of norms.

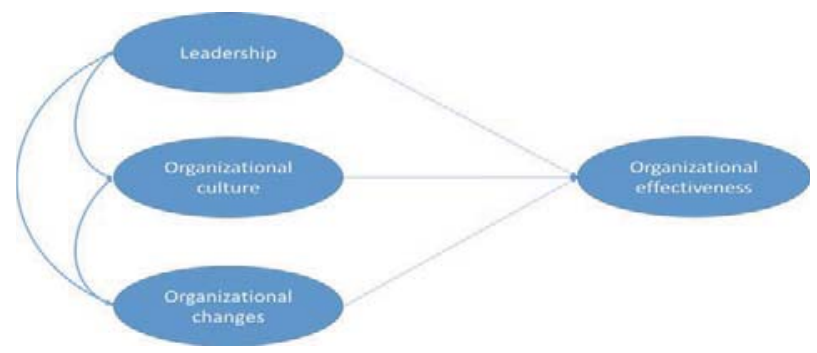

Figure 1. Conceptual model and their influence in organizational effectiveness

Organizational culture includes expectations of an organization, experience, philosophy, and values they carry along, and express the self-image of its inner works.

Definitions regarding organizational culture we encounter since the last century when Homans, 1950: that evaluate in work groups as for example the certain norms of "honest daily work for a right daily payment" which evaluated at the Bank Wiring Room by the studies of the Hauthorn".

Author Tagiuri and Litwin, 1968 emphasize that: "Sense or climate that is transmitted to an enterprise by the physical structure and how members of that organization interact with customers or other persons outside".

Schein, 1968, Van 1979, Ritti and Funkhouser, 1982: "Rules of the game for protection of good relations in the enterprise" Specialized procedures or details" that a newly comer should learn to become accepted member".

Ouchi, 1981; Pascale and Athos, 1981: "Philosophy that leads politics of one organization towards employees and/or clients". While authors Deal and Kennedy, 1982 emphasize, (Deal, T.E. and Kennedy, A.A.,1982).: "Dominant values supported by an enterprise, such as product quality and leadership ".

Safford, 1988; Weick, 1976 "Organizational culture processes of reasoning leads the way organizations need to adapt to the external environment and therefore entails strategy development process ".

Schein, 1985 emphasizes that: "is a model of common base supposing that group learned after it solved the problems of external adaption and internal integration that well functioned sufficiently to be considered valuable and therefore to teach new members the right manner to percept, think and feel regarding these problems".

\section{Some Key Dimensions of Cultural Organizations}

1. Some key dimensions of culture may vary from one company to another in some aspects, (Ferraro. G, Elizabeth. B, 2012):

2. Individual Initiative: the degree of responsibility, freedom and independence that have individuals.

3. Risk Tolerance: the degree to which individuals are encouraged to be innovative and take risks

4. Leadership: the degree to which the organization creates clear objectives and goals.

5. Integration: where units within the enterprise level are encouraged to operate in a coordinated manner.

6. Contact management: the extent to which managers provide clear communication, assistance and support for dependents.

7. Control: a set of rules and laws and the degree of direct supervision that is used to observe and control the behavior of workers.

8. Remuneration system based on the criteria and results of employees.

9. Communication: organization level where communication is limited by a formal hierarchy of command.

10. The margin of conflict: the degree to which employees are able to cope in an open conflict.

If we have a strong culture within the enterprise then she is accepted by all members and should provide motivation and clearance of goals for easier achievement of general goal at the enterprise. Culture is important part of the 
conflict and solving of conflict.

Cultures are as hidden rivers that walk through the life and our relationships and give us the message that create our perceptions, attributes, judgments and ideas of our own and the others. Even though the cultures are powerful often in irresponsible way influence the conflict and efforts for its resolving in invisible way.

The business culture is a problem that usually is neglected by us. Characteristics of small business in Kosova make them oriented towards short-term profit, without long-term vision that often influences for worst in profit and longterm performance. Business culture presents the manner of organizing, planning, control and behavior of the organization in certain situation, (Ademi. B, 2008). Decisions are being taken based to short-term situation.

\section{Impact of Organizational Culture in Enterprise - Case Study Kosovo}

With increasing of the development level of society in Kosova by one side and with increase of variability level in business organizations managers are seeking continuously new ways to generate commitment of the employees in organizational changes; named generation and the use of competitive advantages in a complex and variable market of work.

The impact of organizational culture in the enterprise is the longest process of raising the quality of employees, because it often requires a change in philosophy and, consequently, lifestyle and culture. In fact, the globalization of the economy is one of the main characteristics of today's world and the borders between countries in the global economy disappeared, to put it mildly, are disappearing rapidly, increasing the diversity of employees, who come from countries with cultures different, so recognizing the culture of co-workers, and in particular the users and adapting their behavior is essential for a successful business.

Each company has its own special culture which provides the basis for the recognition of behaviors and a key factor in its success.

Different sectors have different sensitiveness towards requests and the decrease of the buying power. None of the managing activities cannot give expected effects if a condition in which system functions which is the object of managing is not studied(Buqinca. Q, 2006).

Special attention by different researchers in different times took studying of organizational culture and its impact at organizational changes, different studies emphasize that compatibility between the effort for change and the culture is very important criteria to achieve success at the enterprise. In a way that efforts for change get argument being able to bring new forms of culture knowledge and to change culture context in mutual relationship based to some studies of recent times some researchers concluded that organizational culture is determining factor in performance and capability of one organization to realize with success the new process as well as generating of the commitment and improving the performance. Measurements which we made regarding organizational culture were based on dimensions presented by Denison (1990), Mishra \& Denison (1995), and Fey \& Denison (2003), which divide organizational culture in four characteristics as:

$>$ Adaptability, for creating adaptable changes, focus of the enterprise to the consumer trying to predict customer needs in the future.

$>$ Sustainability, means efficient structure, coordination, integration, the ability to deal in critical cases for the enterprise, and core values of the members of the enterprise as a sense of identity.

$>$ Involving, to understand the dedication of employees at work, responsibilities in running the company and sufficient information. Enterprise investment on developing the skills of employees to maintain competitiveness and meet the needs of business, team orientation toward the values of teamwork and achievement of common goals.

$>$ Mission, to understand if employees know where this enterprise is going, if it has strategically direction the enterprise that gives full meaning to the goal and direction beyond long-term vision and satisfaction at work as well as about goals and understandable and measurable objectives to test the progress of the enterprise.

The data show that the four variables affect positively to organizational effectiveness. Independent variables are adaptability, durability, mission and involvement while the dependent variable is organizational effectiveness. Biggest impact belongs to variable "sustainability" using the method of Ordinary Least Squeres (OLS) and through the evaluation of the model of linear regression we present these results in the below shoved scheme in figure 2 . 


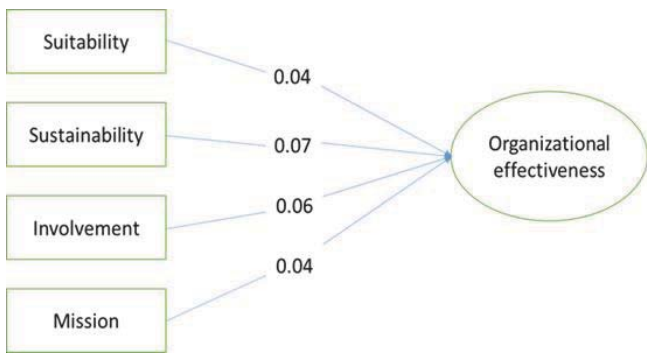

Figure 2. Coefficient of organizational culture variables in organizational effectiveness

Thereby we confirmed that the clear influence of organizational culture ((adaptability, consistency, mission and involvement) in organizational effectively. By received data on the above shown figure we can see clearly that for every increasing unit in independent variable "adaptability" increases with $4 \%$ hanging variable "organizational effectively". While for every increasing unit of the variable "sustainability" we have increasing impact from $7 \%$ in organizational effectively. Also with variable "involvement" for every increase unit of this variable we have positive impact from 6\% in organizational effectively. The last one for every increase unit the variable "mission" impact in organizational effectively is increased for $4.4 \%$.

As a conclusion, organizational culture (adaptability, sustainability, mission and involvement) affect positively to the effectiveness of the enterprise this hypothesis is confirmed. This hypothesis is confirmed because of positive relationships with organizational effectiveness, with independent variables increase organizational effectiveness or increase the dependent variable of the study. All independent variables show consistency in their testing but was observed from the data that the sustainability dimension of organizational culture has a greater impact on organizational effectiveness.

The goal of this study is the influence of organizational culture relationships and its dimensions (adaptability, mission, involvement, and sustainability) in organizational effectiveness of enterprises in Kosovo. Even according to Gillespie and Denison (2007), Saffold, (1988), and Denison (1990), the sustainability of an organization refers to the values and beliefs that promote harmonization and real efficiency, thus organizations are more stable and integrated by providing a safer organizational effectiveness, (Gillespie, M. \& Denison, R, 2007).

\section{Conclusions}

As a conclusion of this study we can conclude that the influence of organizational culture in the enterprise is very important in managing of the quality as a complete system of norms, values, performance, socializing and elements that determine a characterized system at the enterprise. Certain types of cultures are more ready and inclined for change that is requested by time. Even though request to describe a certain culture or to identify possible fields that are connected with initiatives of change.

This study is focused in studying of organizational structure and its influence at the enterprise in particular in enterprises of Kosova, which are part of perceptual perspective, what makes visible the level of difficulty of their measurement in relation to elements of objective perspective. Therefore we can say that the culture of one organization influences in direct manner in all aspects of one business including financial performance and effectively of business process, while some other researches feel skeptical regarding the relationship between organizational structure and performance cause of the lack of convincing evidence.

At the end in a way that the influence at the enterprise to be more effective and sure we will mention three most important features of organizational culture.

$>$ First the organizational culture should be valuable influencing in providing profitable activities at the enterprise or on other elements that provide organizational effectively.

$>$ Second the organizational structure should be unique within each enterprise ensuring that values, norms, socializing not to constrain the culture of the other but to enable diversity and competition of values within the enterprise.

$>$ Third in any form the culture of one organization cannot be imitated in perfect way by other organizations even though one manager may wish to build a new preferred and perfect culture that cannot be achieved because 
the hidden or visible factors that contribute are many.

At the end of this study we can freely conclude that cultures are dynamic and that they change increasing gradually and in continuous way, in respond to external and internal changes. Therefore to give evaluation for organizational culture and its influence in enterprise is complicated in reality in which we are today.

\section{References}

Ademi, B. (2008), Managing of family business, University Fama, Prishtina.

Buqinca, Q. (2006), Managing of organizational systems, Prishtina.

Denison, D. R. (1990), Corporate culture and organizational effectiveness, New York: Wiley.

Denison, D. R., \& Mishra, A. K. (1995), Toward a theory of organizational culture and effectiveness. Organizational Science, p 204 223.

Deal, T.E. \& Kennedy, A.A. 1982. Corporate cultures: The rites and rituals of corporate life. Reading, MA: Addison-Wesley.

Fey, C. F., \& Denison, D. R. (2003). Organizational culture and effectiveness: can American theory be applied in Asia? Organization Science, 14(6), p 686-706.

Ferraro, Gary, Briody, Elizabeth, (2012), The Cultural Dimension of Global Business, 7th Edition, USA.

Gillespie, M. \& Denison, R. (2007), Linking organizational culture and customer satisfaction: Results from two companies in different industries, European Journal of Work and Organizational Psychology, Psychology Press. Taylor \& Francis Group.

Homans, G. C. (1950). The human group, New York: Harcourt Brace.

Muca, Rejnald, Lito, Gerdi (2011), Risks with which face Albanian business and their managing, Finance Department, Economic Faculty, University of Tirana.

Robo, Marsela, Beqiri, Albana, (2014), Fundamentals of entrepreneurship, Textbook Publishing House, Tirana.

Ritti, R. R., \&Funkhouser, G. R. (1982), Ropes to skip and the ropes to know, New York: John Wiley \& Sons, Inc.

Saffold, G. (1988), Culture traits, strength, and organizational performance: Moving beyond strongculture, Academy of Management Review, 13, p $546-558$.

Schein, E.H. 1985, Organizational culture and leadership, 1st ed. Jossey-Bass, San Francisco, CA.

Taguiri, R., \&Litwin, G. H. (1968), Organizational climate: Exploration of a concept, Boston. 